\title{
POLÍTICAS PÚBLICAS PARA LA FRUTICULTURA EN ARGENTINA, 1930-1943
}

\author{
PUBLIC POLICIES FOR THE FRUIT GROWING \\ IN ARGENTINA, 1930-1943
}

\author{
María Silvia Ospital \\ Universidad Nacional de Quilmes, Buenos Aires, Argentina, <sospital@unq.edu.ar>
}

Resumen: El cierre de los mercados internacionales para la producción agraria argentina, consecuencia de la crisis internacional de 1929, obligó al Estado a implantar una serie de medidas alternativas regulatorias de la producción y mercado internistas. Estas prácticas políticas fueron acompañadas por campañas publicitarias que apuntaban a identificar consumo de productos nacionales con una nueva versión del patriotismo. Este artículo se propone realizar algunos aportes sobre esa cuestión, centrándose en las formas en que el Estado nacional -a través del Ministerio de Agricultura- y la dirigencia política y empresarial de la provincia de Mendoza elaboraron la imagen de la Argentina frutícola, productora de uvas de mesa, naranjas y manzanas para el consumo interno, a la vez que la promovían proyectándola como un novedoso renglón de las exportaciones argentinas.

Palabras clave: políticas públicas, fruticultura, técnicos, publicidad oficial.

Abstract: The closing of international markets for Argentine agrarian production forced the Government to implement a series of alternative measures such as production and commerce public regulations, bilateral treaties and the rediscovery of possibilities of the domestic market for national products. Those political measures were supplemented by a variety of advertising campaigns aimed at identifying the consumption of domestic products with a new way of patriotism. This paper aims to make contributions to this matter, focusing in the ways in which both the national government -through its agriculture ministry- and the political and corporate leaderships in the province of Mendoza composed the image of Argentina as an important producer of grapes, oranges and apples, while at the same time they stimulated fruit as a new source of the country international commerce.

Key words: public policies, fruit growing, tecnicians, oficial advertisement.

Fecha de recepción: diciembre de 2011. Fecha de aceptación: marzo de 2012.

Am. Lat. Hist. Econ., año 20, núm. 1, enero-abril, 2013, pp. 78-97 
La fruta es uno de los dones más preciados de la naturaleza argentina. Ninguna otra en el mundo la supera y difícilmente la iguala. Ella ha venido a agregarse ahora a la ya larga lista de las cosas buenas y sabrosas con que nuestra tierra fecunda contribuye a la salud y al bienestar del mundo. Como las carnes y los cereales ayer, como el algodón luego, como mañana, quizá el petróleo, ella es ahora y será de día en día más, uno de los factores primarios de la economía argentina. ${ }^{1}$

\section{INTRODUCCIÓN}

$\mathrm{L}$ os países agroexportadores reaccionaron ante la crisis internacional de 1929-1930, aplicando distintos mecanismos de control y regulación, prestando atención especial a su mercado interno, modernizando sus administraciones y, en una etapa posterior, desarrollando industrializaciones sustitutivas. La instrumentación de medidas propias del intervencionismo de Estado se convirtió en la práctica de economía política universalmente aceptada en el marco de un panorama internacional caracterizado por la contracción del comercio, la repatriación de capitales hacia los países centrales y la caída del patrón oro.

La situación internacional descrita impactó fuertemente en Argentina, tradicional país exportador de materias primas -carnes y cereales-con una relación muy estrecha con el Reino Unido, principal comprador de su producción y poderoso inversor de capitales en infraestructura ferroviaria, actividad financiera y frigoríficos. A los factores exteriores se sumaron problemas internos, agudizados por los enfrentamientos políticos entre el partido en el gobierno, la Unión Cívica Radical, y los grupos conservadores que habían detentado el poder hasta 1916. Las respuestas del presidente Hipólito Irigoyen, anciano líder del radicalismo, resultaban, a los ojos de los sectores tradicionales, absolutamente ineficaces; este conjunto de presiones externas e internas desembocó, en septiembre de 1930, en un golpe de Estado liderado por figuras militares que recibieron el apoyo de los partidos conservadores. Dos años después se procedió a llamar a elecciones nacionales, buscando recomponer el sistema institucional. Los gobiernos que se sucedieron en Argentina desde 1930, tanto el régimen de facto surgido del golpe como las autoridades siguientes, adoptaron rápidamente programas típicos del intervencionismo estatal. Las herramientas básicas esgrimidas ante el impacto de las nuevas condiciones internacio-

${ }^{1}$ Ollivier, "Fruticultura", 1936, p. 263. 
nales abarcaron el control de cambios, la firma de tratados comerciales bilaterales y la instalación de agencias de regulación de la producción y el comercio de los productos agrarios considerados clave. En este sentido es posible establecer una continuidad de acción entre el gobierno de facto instalado en 1930 y los gobiernos constitucionales, de dudosa legitimidad, que funcionaron desde $1932 .^{2}$

Si bien una importante porción de las políticas implementadas buscaba recomponer la vapuleada economía pampeana orientada a la exportación, la acción del Estado nacional se extendió a las economías regionales. Diversas juntas reguladoras fueron creadas para controlar la yerba mate, el algodón, el azúcar y el vino, fiscalizando cantidades producidas y precios vigentes, apelando a la destrucción de plantaciones o al desperdicio de lo producido cuando las condiciones parecían exigir tales extremos. Los gobiernos provinciales, con el apoyo de los empresarios más importantes de las producciones citadas, acompañaron estas medidas dictando legislaciones complementarias e interviniendo activamente en cuestiones económicas. ${ }^{3}$

En la búsqueda de alternativas comenzaron a promocionarse, desde el Estado nacional, producciones agrícolas que anteriormente habían recibido poca atención de parte del poder central. En ese sentido corresponde destacar el impulso otorgado al crecimiento de la fruticultura en un intento de avanzar en varios frentes. Por un lado se apuntaba al mercado interno, que se había convertido -frente a las dificultades que afrontaba el comercio hacia el exterior- en un destino privilegiado para el consumo de la producción nacional de alimentos; ${ }^{4}$ por otro, la intención parecía estar centrada en las posibilidades de los frutos de convertirse en un próspero renglón de las exportaciones argentinas, estimulando desarrollos regionales en algunos casos -Cuyo, Entre Ríos y Corrientes- e interviniendo en espacios que, hasta ese momento, habían crecido al compás de la actividad privada exclusivamente, como era el caso del Alto Valle de Río Negro. Instrucciones a los agricultores, enseñanzas sobre técnicas de cultivo y defensa contra plagas, disposiciones sobre empaque y envasado para asegurar el traslado entre los centros de producción y los mercados consumidores, se elaboraron y difundieron para afirmar, extender y mejorar el cultivo de uvas y manzanas en Cuyo, cítricos en Entre Ríos y Corrientes, y peras y manzanas en el valle de Río Negro.

\footnotetext{
${ }^{2}$ Sobre el tema véanse O'Connell, "Argentina”, 1984, pp. 479-514, y Schvarzer, Industria, 1996, pp. 153-186.

${ }_{3}^{3}$ Para la repercusión de la crisis en el interior, véase Girbal, Ospital y Zarrilli, Miradas, 2005.

${ }^{4}$ Sobre las políticas elaboradas para promocionar los productos nacionales en el mercado interno, véase Girbal y Ospital, "Vivir", 2005, pp. 49-66.
} 
En este artículo se intentará analizar, además de las medidas emanadas del gobierno nacional, algunos aspectos de las respuestas elaboradas en la región vitivinícola, especialmente la provincia de Mendoza. Aunque las referencias al proceso mendocino son más escuetas, su inclusión resulta relevante por varios motivos. La provincia era el principal centro productor de vino de Argentina, y lo había sido en su condición de proveedora de la bebida para el mercado interno que había logrado incorporarse desde finales del siglo XIX al modelo económico instaurado desde la región pampeana. Desde poco antes de 1930 la agroindustria vitivinícola atravesaba situaciones críticas a las que se sumaron las consecuencias de la crisis general. En esa disyuntiva, dirigentes políticos y empresarios locales importantes desplegaron, en consonancia con las iniciativas emanadas del gobierno central, una serie de acciones destinadas a modernizar el aparato de gobierno, otorgar nueva dignidad a la vitivinicultura y fomentar el turismo regional. Estas disposiciones abarcaron campañas publicitarias a favor del consumo de vinos nacionales, operaciones y consejos destinados a mejorar la calidad de los productos elaborados, diversos intentos de organización racional de la producción, así como la construcción de una mitología asociada al cultivo de la vid y la elaboración de vinos con el establecimiento de la fiesta de La Vendimia. El grupo político que ocupó el poder provincial a partir de 1932 coincidía con el gobierno central en la necesidad de poner en práctica una activa política intervencionista.

A la vez que se proponían, discutían y aplicaban estas iniciativas, la dirigencia empresarial local propició el desarrollo de la fruticultura, recuperando viejas prácticas de cultivos artesanales, sobre los que trabajó para convertirlos en una alternativa productiva, capaz de apuntalar una vitivinicultura en crisis. Así como los quinteros y fruticultores de la provincia de Buenos Aires habían cultivado viñas e intentado producir vino en forma competitiva para aprovechar su cercanía a los grandes mercados de consumo, los vitivinicultores mendocinos -como en un juego de espejoscomenzaron a destinar parte de sus fincas al cultivo de frutas, reservadas al consumo inmediato o a ingresar en las plantas elaboradoras de una incipiente industria conservera. Sus intentos resultaron mucho más exitosos que los de los quinteros bonaerenses y Mendoza se convirtió, junto con el territorio nacional de Río Negro ${ }^{5}$-también región vitivinícola- en una de las principales provincias productoras de duraznos, ciruelas y tomates en conserva.

\footnotetext{
${ }^{5}$ Sobre fruticultura en el Alto Valle de Río Negro son centrales los siguientes trabajos: Bandieri y Blanco, "Fruticultura", 1991, y "Pequeña" 1998, y Bendini y Pescio, Trabajo, 1996. En esta contribución el análisis de la actividad en la zona se limita al estudio de las políticas, elaboradas por el gobierno nacional, destinadas a publicitar la región como la principal productora de frutas para exportación.
} 
En este artículo se pretende comentar el conjunto de medidas que, en el sentido indicado, fueron aplicadas por funcionarios y técnicos del Ministerio de Agricultura de la Nación, a la vez que se propone estudiar el conjunto de afirmaciones, discursos y medidas concretas elaborados por autoridades y productores regionales mendocinos en el campo de la actividad frutícola como parte de las políticas complementarias de la regulación. Las políticas públicas sobre fruticultura, considerando la actividad como alternativa productiva frente a la crisis y como complemento imprescindible de las medidas anticíclicas, se convierten en los hilos conductores de las páginas siguientes, conjugando miradas sobre el accionar del Estado nacional y las prácticas emprendidas por una dirigencia provincial.

\section{POLÍTICAS EN CUESTIÓN FRUTÍCOLA}

\section{Antecedentes y propuestas}

En el ámbito nacional es posible rastrear impulsos a la producción frutícola desde la década de 1920, por lo menos. Junto a los cítricos mesopotámicos, la región isleña de la desembocadura del Paraná había sido la tradicional proveedora de fruta fresca para los centros urbanos del Litoral, pero esta circunstancia no había implicado la adopción de políticas especiales ni había concentrado las preocupaciones de los empresarios. A partir de los años señalados, tanto la Sociedad Rural Argentina como oficinas especiales del Ministerio de Agricultura comenzaron a considerar la cuestión. Varios artículos del técnico Carlos D. Girola aparecieron en diversos números de la publicación Museo Agrícola de la Sociedad Rural, mientras la sección Propaganda e Informes del Ministerio de Agricultura dedicaba algunas de sus circulares a las temáticas relacionadas con el cultivo de las frutas. ${ }^{6}$ Es posible vincular estas iniciativas con las preocupaciones y consejos expresados por intelectuales y políticos que, desde 1914, habían advertido sobre el fin de la expansión horizontal de la producción agraria y la necesidad de vivir con lo nuestro y desarrollar las "industrias naturales".

Las circunstancias cambiaron a partir de 1930. La contracción del comercio internacional, con el consiguiente cierre de mercados externos para la producción agraria argentina, determinó una revalorización del

\footnotetext{
${ }^{6}$ Girola, Museo, 1920, 1922, 1925-1926, y 1929. Ministerio de Agricultura de la Nación, Secc. Propaganda e Informes, Circulares 30, 742 y 823.

${ }_{7}^{7}$ Las referencias a los escritos y propuestas de Alejandro Bunge y su revista resultan imprescindibles. Sobre este y su Revista de Economía Argentina, véase Llach, Argentina, 1985.
} 
mercado interno para esas mercaderías. Estado y empresarios apoyaron importantes campañas publicitarias sobre productos argentinos como la carne, la leche, el algodón, el azúcar y el vino, sin distinción de marcas, en un intento de convencer al público consumidor de la vital importancia de vivir con lo nuestro. Es en ese contexto que debe considerarse el interés despertado por un desarrollo racional y eficiente de la fruticultura, desarrollando y satisfaciendo la demanda interna para orientar luego otras frutas y otras zonas productoras hacia la comercialización externa.

En el debate sobre la importancia de fomentar la fruticultura participaron técnicos especializados e intelectuales vinculados a sectores empresarios. A sus planteamientos se agregaron las propuestas provenientes, directamente, de políticos profesionales. El poder ejecutivo nacional presentó algunos proyectos de ley en la Cámara de Senadores, reglamentando el comercio de frutas y hortalizas en el territorio del país, en agosto de 1936 y volviendo sobre el tema, con el agregado de consideraciones sobre su industrialización, en julio de 1938.

Diputados nacionales, por su parte, habían presentado iniciativas en su propia cámara. Entre ellas mereció atención la propuesta del diputado por Tucumán, J. Simón Padrós, proponiendo la construcción, por cuenta del Estado nacional, de frigoríficos regionales para frutas, a ubicarse en el territorio de Río Negro y en la provincia de Mendoza. La lectura de los fundamentos de la medida pone de manifiesto la orientación que se aspiraba a darle al comercio de frutas, es decir, la exportación. La instalación de las plantas en las zonas productoras apuntaba a asegurar la correcta conservación de peras y manzanas para su posterior envío a los mercados externos. Cabe destacar que las frutas rionegrinas ya constituían un rubro exportable desde principios de la década de 1930. Lo novedoso, en este caso, lo constituye la decisión de otorgarle participación al Estado nacional en esa materia.

El mismo proyecto proveía información respecto a los frigoríficos ya existentes. De los 38 frigoríficos en funcionamiento, 22 estaban instalados en la ciudad de Buenos Aires, siete en la provincia de Buenos Aires, cuatro en Santa Fe, solamente dos en Mendoza y ninguno en Río Negro. ${ }^{8}$ En cuanto a la capacidad de almacenamiento, las tres cuartas partes del total correspondían a los establecimientos capitalinos, sumados a las tres cámaras de Avellaneda. Es interesante remarcar cuáles eran los lugares elegidos para la construcción de los nuevos frigoríficos: un territorio nacional, con dependencia directa del Estado nacional, donde actores privados vinculados al capital inglés ya venían desarrollando el cultivo de frutas con destino a la exportación y una provincia que buscaba, en la fruticultura, una al-

\footnotetext{
${ }^{8}$ Propuesta ante la Cámara de Diputados, en Padrós, "Frigoríficos”, 1938, pp. 1787-1803.
} 
ternativa superadora de la crisis de la vitivinicultura. Sometido el proyecto a la consideración de la Dirección de Frutas y Hortalizas, correspondiente del Ministerio de Agricultura, esa oficina lo apoyó decididamente, destacando la importancia de la colaboración del Estado con los productores, favoreciendo la inversión particular y la formación de grupos cooperativos de fruticultores. La iniciativa fue aplaudida por los técnicos del Ministerio de Agricultura, sin embargo, el proyecto no prosperó.

\section{El Ministerio en acción}

En el marco de las políticas que definieron al Estado interventor de esos años, al Ministerio de Agricultura le correspondió una participación estratégica. Frente a los problemas que afectaban al sector agrario, debió asumir la responsabilidad de implantar políticas que contribuyeran a mejorar esa situación. Cambios en su organización burocrática, nuevas oficinas y activas campañas publicitarias destinadas a productores y público en general, caracterizaron sus acciones a partir de $1933 .^{9}$

En materia de publicaciones, si bien el organismo poseía su propia imprenta y oficina respectiva, no desdeñaba recurrir a otros medios periodísticos para difundir sus consejos y actividades. El análisis de las políticas del Ministerio -en materia frutícola, en el caso que nos ocupa- requiere la consulta de esa otra documentación, además de la emanada directamente de la oficina pública. Las fuentes a examinar son la revista La Chacra, que comenzó a aparecer en 1930, y la revista Servir, órgano de la Escuela de Estudios Argentinos. Mientras la primera dedicaba varias páginas de sus números mensuales a reproducir disposiciones del Ministerio y a comentar sus iniciativas, en la segunda escribieron destacados funcionarios ministeriales.

La revista La Chacra se proponía hacer llegar a chacareros, pequeños productores agrícolas y criadores de aves de corral -y a sus familias-informaciones, consejos y orientaciones útiles para el mejor aprovechamiento de sus emprendimientos productivos. Se trataba de un semanario dirigido a un público rural, aunque extendido a todas las personas interesadas en estas cuestiones, incluyendo a los habitantes de la ciudad. Empezó a publicarse en 1930 -y aún continúa vigente- como una nueva manifestación del empuje y diversidad de intereses de la editorial Atlántida, fundada por Constancio C. Vigil en $1918 .{ }^{10}$ Era frecuente que en ella se publicaran

\footnotetext{
${ }^{9}$ Sobre los orígenes y cambios en la década de 1930 del Ministerio, véanse Ruffini, "Nuevo”, 1998, pp. 373-382, y Blacha, "Burocracia”, 2008, respectivamente.

${ }^{10}$ Véase Gutiérrez, "Revista", 2005, pp. 19-62.
} 
medidas y disposiciones ministeriales. Así, en varios números de 1937 se reprodujo el decreto reglamentario núm. 96066 promulgado en diciembre de 1936, sobre exportación de fruta fresca, con la firma del presidente Agustín P. Justo y del ministro de Agricultura Miguel Ángel Cárcano. Con gran minuciosidad, se establecían las condiciones de aptitud que manzanas, peras, uvas y cítricos -los principales renglones de ese comercio- debían reunir para poder partir de los puertos del país. También se especificaban las características de los envases apropiados para las remesas. ${ }^{11}$

En otra manifestación de las fluidas relaciones entre el Ministerio y la revista, en agosto de 1939 se publicó la estadística de exportación de fruta durante el periodo de 1930-1938, proporcionada por el organismo oficial. ${ }^{12}$ El total de toneladas salidas del puerto de Buenos Aires y sus respectivos destinos, con Brasil e Inglaterra como principales receptores, mostraban un crecimiento importante año tras año. La publicación demostraba su orgullo por estos logros afirmando: "se nos respeta en cuanto a nuestra producción de cereales, por lo que se nos llama el granero del mundo, y vamos en camino de ser una nueva California en la producción de frutas". ${ }^{13}$

Por su parte, la revista Servir comenzó a publicarse en 1936, en forma mensual, para difundir el ideario de la recientemente creada Escuela de Estudios Argentinos, fundada para "contribuir al estudio y a la difusión del conocimiento de los problemas técnicos y científicos nacionales y a exaltar en los intelectuales argentinos el sentimiento de su responsabilidad social, brindándoles oportunidad y estímulo para ser útiles en horas tan difíciles". ${ }^{14}$

Surgida de las preocupaciones que las repercusiones de la crisis generaba en sectores intelectuales y empresariales de raigambre conservadora, la institución utilizaba su revista como principal herramienta de acción. La misma estaba estructurada en secciones, que se formaban con distintas contribuciones publicadas en números alternados del órgano de prensa. Toda una sección estuvo dedicada a la temática de la fruticultura. La importancia de la cuestión para los intelectuales concentrados allí quedó de manifiesto desde el primer número del mensuario. Un artículo del ingeniero agrónomo Arnaldo M. Lutscher, reproducción de una conferencia pronunciada en diciembre de 1934, señala la importancia económica del cultivo de frutas para el país, al comparar los valores alcanzados por la importación del producto, en contraste con las insignificantes cifras corres-

\footnotetext{
11 "Decreto", 1937, núm. febrero, pp. 44-45, y núm. mayo, pp. 35-36.

12 "Riquezas", 1939, pp. 79-81.

${ }^{13}$ Ibid.

14 "Editorial", 1936.
} 
pondientes a la exportación de ese rubro. ${ }^{15}$ Lutscher ponderaba "la tenaz acción oficial" que desarrollaba el Ministerio de Agricultura -él mismo era funcionario de la repartición-y el interés demostrado por algunas provincias, así como el "ponderable esfuerzo de algunos industriales" en la búsqueda de mercados externos para su producción. ${ }^{16}$

Ese mismo año el agrónomo Adrián Ollivier (hijo) presentaba el panorama de ideas que, respecto de la fruticultura y su futuro económico, sostenía el conjunto de técnicos estatales. Ollivier era jefe de la Dirección de Contralor de la Producción Frutícola, oficina ministerial encargada del tema. Luego de resaltar las particularidades del cultivo de este ramo, destacaba la tarea inteligente de los fruticultores que controlaban plagas y enfermedades, comprendiendo que "el mejor precio lo da la calidad y que la calidad no se obtiene sino a base de trabajo y de cuidados sanitarios". ${ }^{17}$ A continuación insistía en la importancia de la compilación prolija de información estadística, indicando que solamente la provincia de Mendoza realizaba tales tareas.

La relevancia que el mercado interno adquiría para la fruta nacional era un rasgo especialmente destacado en el estudio. El técnico remarcaba la importancia de construir asociaciones de productores para desarrollar planes racionales de distribución y una propaganda eficaz. Solamente por ese camino se aseguraría el éxito de la tarea y se conquistaría el favor de los consumidores. En las consideraciones finales se revalorizaba la producción de frutas argentinas, augurando para ellas un destino semejante al de las carnes y cereales en el pasado, cuando uvas, peras y manzanas se proyectaran a los mercados externos, convirtiéndose "en uno de los factores primarios de la economía argentina".

Ambas publicaciones coincidían en destacar la importancia de la exportación de frutas para la economía del país, pero mientras La Chacra se dedicaba a explicar y recomendar las mejores formas de cultivar y empacar fruta -en un todo de acuerdo con su línea editorial- y festejaba los logros en la materia como lo hacía con las mejoras introducidas en la cría de animales de granja o gusanos de seda, Servir presentaba la cuestión como parte de las reformas imprescindibles que trataba de hacer llegar

${ }^{15}$ Lutscher, "Aspectos", 1936, pp. 90-95. En ese mismo número se reprodujo un aviso de la División de Contralor de Producción Frutícola del Ministerio de Agricultura de la Nación destacando la importancia de la "fruta argentina para exportación". El dibujo mostraba a un cultivador derramando sobre el globo terráqueo las frutas contenidas en una caja: uvas, duraznos, peras y ciruelas.

${ }^{16}$ Denominar industriales a los cultivadores de frutas de cualquier tipo, aunque no se ocuparan de ninguna fase de la industrialización, hace referencia a la utilización intensiva de mano de obra que la actividad requería, a diferencia de la tradicional agricultura cerealera y maicera.

${ }^{17}$ Ollivier, "Fruticultura", 1936, pp. 237-264. 
al poder político, a fin de lograr el crecimiento conjunto de las distintas regiones del país.

La creación de nuevas oficinas en el interior del Ministerio de Agricultura se inició con el establecimiento de la sección Comercial de la Fruta, constituida por decreto del poder ejecutivo nacional en febrero de 1934 . Sus funciones abarcaban aspectos técnicos y comerciales, es decir, que se ocuparía de racionalizar métodos productivos mientras fiscalizaba rigurosamente la calidad de las frutas argentinas destinadas a la exportación. ${ }^{18}$ Creada como organismo ejecutivo de la Comisión Nacional de Fruticultura, pasó a ser la División de Contralor de la Producción Frutícola para convertirse poco después, a partir de enero de 1936, en Dirección de Frutas y Hortalizas. La repartición "mantiene íntimo contacto con el productor y el comerciante, a los que lleva orientaciones claras y precisas". ${ }^{19}$ Esa labor se realizaba a través de la publicación de un boletín informativo mensual y de ediciones especiales indicadoras de las variedades más adecuadas para las distintas zonas del país. Además atendía las preguntas de los productores en un consultorio técnico. Al comentar su funcionamiento, en 1938, las autoridades ministeriales insistían en la utilidad del proyecto de Ley de Frutas y Hortalizas que el poder ejecutivo había presentado en el Congreso en 1936, aún no sancionado. Esta ley permitiría a esta dirección "llevar a la industria frutícola nacional a la máxima perfección posible en todos los aspectos del comercio de la materia". ${ }^{20}$ Mientras tanto, la oficina, es decir, la Dirección de Frutas y Hortalizas, continuaba sus funciones que consistían, básicamente, en "estudiar los problemas comerciales de la fruta relacionados con los mercados interiores y los exteriores; organizar los censos de las plantaciones frutales y compilar los datos de la producción; establecer para cada especie frutal cuáles eran los zonas óptimas y marginales desde el punto de vista comercial; fiscalizar en los viveros la producción de plantas frutales destinadas a plantaciones comerciales, etcétera". ${ }^{21}$

Gran parte de los consejos y orientaciones a productores eran canalizados en los almanaques que la Dirección de Propaganda y Publicaciones del Ministerio editaba anualmente. Estaban dirigidos a comerciantes, cooperativas agrícolas, sociedades rurales, institutos de enseñanza, "jefes de estación de ferrocarriles", que los recibían con un descuento de $20 \%$ sobre su precio, mientras se vendían a bancos, oficinas agronómicas regionales, veterinarios, escuelas de agricultura y viveros. Se buscaba asegurar una amplia difusión del almanaque. La cuestión frutícola ocupaba una parte

\footnotetext{
${ }^{18}$ Herl, Ex Ministerio, 2008.

${ }^{19}$ Ibid.

${ }^{20}$ Almanaque, 1938, p. 79.

${ }^{21}$ Herl, Ex Ministerio, 2008.
} 
importante de su contenido. El ejemplar de 1937, por ejemplo, publicaba en sus primeras páginas un aviso de la Dirección de Frutas y Hortalizas aconsejando el consumo de frutas en las comidas para mejorar la salud. Bajo la admonición: "iFRUTA! del árbol a la mesa", instaba a la población a comprar "fruta buena y barata directamente al productor" siguiendo las instrucciones de la oficina ministerial..$^{22}$

Más importante desde el punto de vista científico y económico era el extenso artículo referido a los tipos de frutas aptos para ser cultivados en las distintas regiones del país, con indicaciones especiales orientadas a asegurar una explotación racional y el éxito comercial. Para las provincias de Cuyo se recomendaban variedades de manzanas, peras y ciruelas; manzanas, peras y membrillos se recomendaban también para los territorios de Río Negro y Neuquén, mientras se proponían diversas especies de duraznos para la provincia de Córdoba. ${ }^{23}$ Como buen almanaque, se indicaban las principales actividades agrarias a realizarse cada mes, incluyendo tratamientos sanitarios, podas, cosechas y demás trabajos frutícolas. El almanaque de 1938 incorporaba consejos sobre otros cultivos menos conocidos, como ciruelos y fresas. Además traía un largo artículo sobre el calendario agrícola para la región del Delta, tradicional zona productora de frutas para el mercado interno. ${ }^{24}$

En 1937 un decreto del ejecutivo reorganizó el Ministerio, agrupando sus oficinas en dos grandes divisiones. Se buscaba jerarquizar la repartición modernizando su funcionamiento y haciéndolo más eficiente. Entre 1935 y 1938 el ministro del ramo fue Miguel Ángel Cárcano, claro representante de los sectores conservadores vinculados estrechamente al agro. Una de sus iniciativas fue la creación de una revista gráfica mensual, llamada $M A N$-sigla que identificaba al Ministerio de Agricultura de la Nacióncon el propósito de "hacer conocer en tal forma la acción desarrollada por el poder ejecutivo en beneficio de la producción, industria y comercio del país, sirviendo especialmente de vehículo de propaganda en el exterior" ${ }^{25}$

Editada por la Dirección de Propaganda y Publicaciones del Ministerio, se presentaba como MAN. Al Servicio de la Riqueza Argentina, y en sus páginas las fotografías ocupaban mucho más espacio que los textos. En varios números se reproducían obras pictóricas de artistas argentinos destacados; el ejemplar de marzo de 1937 -primero de la serie- mostraba el cuadro Chacareros, de Antonio Berni.

${ }^{22}$ Dirección, "Fruta", 1937, p. 18.

${ }^{23}$ Ibid., pp. 213-221.

${ }^{24}$ Véase en Almanaque, 1938, pp. 357-369.

25 “Presentación", 1937, p. 1. 
En sintonía con las preocupaciones de la época, junto a las esperadas referencias a la producción ganadera y a los cereales, las frutas argentinas aparecían repetidamente en distintos artículos. Con el título Fruta sana, buena y barata, se iniciaba la temática. Esta era la consigna de la campaña nacional "a favor del consumo de la fruta, mediante afiches, folletos y propalaciones radiotelegráficas, dirigidas tanto al público como a los productores". Aunque se apuntaba directamente al mercado interno, la nota se ocupaba especialmente de remarcar la vocación exportadora que guiaba la acción del Ministerio en cuestiones frutícolas. De importador de frutas, el país se había convertido en exportador y vendía uvas, peras, manzanas y pomelos a Inglaterra, Brasil, Estados Unidos, Francia y otros mercados europeos y sudamericanos. El aumento en las cifras de exportación (se habían enviado al exterior 10245 toneladas en 1931 y 27616 en 1936) se debía "a la intensa labor de los fruticultores nacionales, orientados por la Dirección de Contralor de la Producción Frutícola". Normas sobre envasado y creación de cursos prácticos de empaque habían colaborado para que la producción argentina llegara "cada vez en mejores condiciones a su punto de destino". ${ }^{26}$

En casi todos los envíos de ese año aparecieron referencias a los frutales argentinos. Las naranjas de Corrientes, enviadas en gran cantidad al "gran mercado de consumo y distribución que es Buenos Aires", compartían espacios con las peras (fuente de "salud y placer") y los limones del Delta, Entre Ríos y Tucumán. ${ }^{27}$

La primera edición de 1938 dedicaba un extenso artículo a destacar los cambios ocurridos en el territorio nacional de Río Negro. Una importante fotografía del ministro Cárcano, rodeado de pobladores locales, se superponía a una imagen del puente que unía a la ciudad de Cipolletti con Neuquén, con el agregado de un grupo de sonrientes niños. El texto subrayaba las modificaciones: "de zona especialmente ganadera (el territorio) se ha transformado en una de las principales regiones frutícolas del país, con más de 20000 ha de árboles frutales; sus manzanas, peras y cerezas son de notable calidad y están encontrando mercados muy favorables en el exterior" ${ }^{28}$

El mensaje parecía claro, productores esforzados y funcionarios dedicados lograban, en una tarea conjunta, reconfigurar el espacio económico y así incorporar nuevos y provechosos renglones al comercio de exportación. Se trataba, en realidad, de una exageración orientada a destacar el accionar del Ministerio en un área que, para la fecha, ya había consolida-

\footnotetext{
26 "Fruta", 1937, s. p.

${ }^{27}$ Revista MAN, núms. abril, junio, julio y noviembre de 1937.

28 "Río", 1938.
} 
do su desarrollo frutícola destinado, en gran medida, al mercado externo. Empresas vinculadas al Ferrocarril Sud, de capital inglés, así como la firma comercializadora Argentine Fruit Distributors habían sido los promotores de ese desarrollo.

Otras zonas y otras frutas desfilaban por las páginas de $M A N$, la publicación del Ministerio de Agricultura, remarcando la importancia de las medidas que aseguraban calidad del producto y óptimas condiciones de embalaje y transporte. Peras, prolijamente empaquetadas y puestas en el puerto; "exquisitas manzanas de las más finas variedades"; uvas de mesa, exportadas a Estados Unidos y Brasil, mercados conquistados "por su excelencia y su buena presentación", recibían su cuota de publicidad. ${ }^{29}$

Durante el año siguiente el enfoque derivó hacia la industrialización de la fruta. Varias notas comentaban la aptitud de los duraznos y peras nacionales para ser enlatados o desecados, conquistando mercados extranjeros bajo esta presentación, "garantizada por modernas disposiciones que reglamentan su producción". Fotografías de secaderos de ciruelas y uvas en San Rafael, con abundante presencia de mano de obra femenina, completaban el mensaje. ${ }^{30}$

Un cierre apropiado para esta minuciosa enumeración es el comentario que acompañó un artículo sobre peras argentinas para exportación, "de aroma imponderable y sabor delicadísimo". En él se resumía la orientación de la política oficial en materia frutícola, tal como se la entendía desde el Ministerio de Agricultura: "El Estado se preocupa por que el fruticultor le dedique los mayores cuidados culturales, pues interesa fundamentalmente que la excelente calidad de la fruta nacional no decaiga ante el consumidor de ultramar." 31

\section{Fruticultura en Mendoza}

La puesta en práctica de las políticas de regulación, en el caso de la vitivinicultura, principal producción de Mendoza, se inició con la creación de la Junta Reguladora de Vinos en 1935. Su acción, orientada a evitar o, al menos, paliar, los modos en que las sucesivas crisis de superproducción afectaban negativamente los precios de los vinos, consistió en la extirpación de viñas, el derrame de vinos y la prohibición de reemplazar, en las hectáreas despobladas, los antiguos cultivos por nuevas plantaciones de cepas. Aunque aplaudidas oficialmente por los dirigentes políticos locales, estas

\footnotetext{
${ }^{29}$ Revista $M A N$, núms. marzo, abril y julio de 1938 .

${ }^{30}$ Revista $M A N$, núms. febrero y marzo de 1939.

31 "Peras", 1939.
} 
medidas fueron resistidas y criticadas por productores pequeños y viticultores sin bodega, los sectores más perjudicados por estos procedimientos. ${ }^{32}$

La clase dirigente local, conformada por políticos y empresarios bodegueros unidos por una estrecha red de alianzas familiares y comerciales, comenzó -a partir de ese momento- a desarrollar estrategias alternativas que le permitieran suavizar las aristas más ásperas de la crisis. Para ello las autoridades promulgaron nuevas disposiciones en materia administrativa y económica, destinadas a modernizar el funcionamiento del gobierno provincial, adaptándolo a las reglas de un modelo más intervencionista, mientras colaboraban con los sectores empresarios en la promoción de la fruticultura. $^{33}$

Al finalizar la presidencia de Agustín P. Justo se publicó un volumen de homenaje al funcionario saliente, de clara y propagandística intención electoralista. Diversos capítulos estuvieron dedicados a las provincias argentinas, sus autoridades y sus municipios. El mensaje apuntaba a mostrar un país integrado y exitoso, que había superado sus problemas bajo la "preclara e iluminada guía" de los dirigentes políticos neoconservadores. La sección referida a Mendoza designaba al periodo de 1932-1939 como la época de "tres gobiernos de orden que comprenden un ciclo de progreso de la provincia". Los gobernadores en cuestión habían sido Ricardo Videla, Guillermo C. Cano y Rodolfo Corominas Segura, en funciones en el momento de la publicación. Dirigentes todos ellos del Partido Demócrata Nacional, tenían viejos y aceitados lazos con la clase empresarial vitivinícola. Es interesante destacar que el texto presentaba a la nueva etapa como "la reiniciación del ciclo de progreso iniciado durante la gobernación ilustre de Civit, propulsor magnifico del adelanto mendocino". ${ }^{34}$

En consonancia con los términos usados en las primeras páginas, la publicación continuaba detallando los progresos de la provincia, su ajustado ordenamiento financiero, el conjunto de obras públicas y de embellecimiento de las ciudades, la extensión de las obras viales. También, en concordancia con los lineamientos de la política nacional, destacaban las virtudes provinciales en tanto centro turístico en crecimiento. Al hablar de la industria vitivinícola afirmaba que "la acción del gobierno ha hecho desaparecer para los productores vitivinícolas el fantasma de la superproducción". A la "acertada" orientación impulsada por las autoridades nacionales, debía sumarse la "meticulosa" labor de control de calidad de los vinos realizada por el gobierno provincial, sin perder de vista el "progresista esfuerzo" de los industriales locales.

\footnotetext{
${ }^{32}$ Sobre la acción de la Junta en Mendoza, véase Mateu, "Vitivinicultura", 2005.

${ }^{33}$ Sobre los cambios introducidos por el gobierno provincial, véase Ospital, "Más", 2007.

${ }^{34}$ Justo, Momento, 1939.
} 
Los comentarios sobre la fruticultura y su desarrollo estaban incorporados en las descripciones de algunos de los municipios de la provincia. El "marcado" adelanto de General Lavalle se explicaba por las obras de riego iniciadas, que tendrían una favorable incidencia en la fruticultura local. Uvas de mesa, sandías y melones completaban el escenario productivo de la región, junto con la vitivinicultura.

La zona de San Rafael era descrita con detalle. Después de remarcar el continuado progreso de la región desde principios del siglo XX, el apartado proporcionaba datos estadísticos precisos. En cumplimiento de las leyes de regulación, se había extirpado aproximadamente la mitad de las hectáreas de viñas de vinificar existentes en 1935. De algo más de 13000 ha habían quedado 7200 con uvas para vinificar y 2000 con viñas de uvas de mesa. En compensación, las hectáreas plantadas con frutales en plena producción alcanzaban las 10000 ha. Las cifras de frutas frescas, incluyendo uvas de mesa, exportadas fuera de la provincia, superaban los 24000000 de $\mathrm{kg}$, mientras una fábrica de extracto de tomate, el establecimiento Cirio, había iniciado muy exitosamente la venta al exterior de su producción. Si bien la vitivinicultura continuaba siendo la actividad más importante del municipio, la producción de frutas y la industria de conservas, sobre todo de tomates, había adquirido proporciones muy importantes. ${ }^{35}$

Resulta claro, en este ejemplo, el proceso de despegue del cultivo de frutas como sustitutivo o complementario de una viticultura que debía reducirse en extensión y una industria bodeguera que debía controlar la cantidad de litros de vino que volcaba al mercado. Las condiciones naturales de la región mendocina permitían el pasaje de un cultivo a otro, estrategia económica apropiada y que los empresarios más importantes -tanto locales como de otras partes del país- emprendieron con entusiasmo. Datos de la zona de Luján de Cuyo muestran caminos semejantes. El establecimiento vitivinícola del vasco navarro Gaudencio Hugalde poseía 56 ha de uvas para vinificar, seis hectáreas de uvas de exportación y seis hectáreas de frutales. La bodega adjunta elaboraba $16000 \mathrm{hl}$ de vino "de la mejor calidad" gracias a sus adelantos tecnológicos. La empresa La Flor de Cuyo, de propiedad de Leoncio Arizu, de familia con larga y destacada actuación en la vitivinicultura, también combinaba superficies plantadas con uvas viníferas con otras dedicadas a las uvas de exportación, producción que era remitida a los "principales mercados consumidores del extranjero" ${ }^{36}$

${ }^{35}$ El artículo añadía que la Sociedad Anónima Argentine Fruit Distributors, con sede central en Río Negro, poseía en San Rafael, el secadero de frutas más importante de la región, mientras el Frigorífico Swift de La Plata construía instalaciones para la industrialización de frutas. Para un estudio de la acción de esta compañía de capitales británicos dependiente de la empresa del Ferrocarril del Sur, véase Bandieri, Historia, 2005, pp. 278-289.

${ }^{36}$ Véase Justo, Momento, 1939. 
Si el empresario vitivinícola -dueño de grandes extensiones de viñas, bodeguero próspero o propietario de tierras e industrias a la vez- que extendía sus actividades también a la producción frutícola resulta un actor social fácilmente identificable, fueron menos los hombres de negocios dedicados con exclusividad al cultivo, industrialización y comercialización de frutas. Representante de este último tipo fue Bruno Della Santa, nacido en Buenos Aires de ascendencia italiana, que concentró su actividad económica en la importación y exportación de frutas. Vinculado con importantes firmas mendocinas, fue fundador de la Bolsa de Comercio de Mendoza y de la Corporación Mixta de Fruticultores de la provincia. ${ }^{37}$

Con intenciones de propaganda partidaria semejantes a las atribuidas al libro de homenaje al presidente Justo, el gobernador mendocino Guillermo G. Cano ordenó la publicación, en 1938, de una compilación de su acción de gobierno. ${ }^{38} \mathrm{En}$ el apartado correspondiente al trabajo del Ministerio de Industrias y Obras Públicas se hacía referencia a la sanción y aplicación de la ley 1165, orientada a "afianzar y fomentar esta industria [la de la fruta], la segunda en importancia que hay en la provincia". Se buscaba estimular a los productores para que mejoraran sus cultivos, a la vez que se controlaba cuidadosamente el empaque de la fruta para asegurar su llegada, en óptimas condiciones, a los lugares de consumo. Fotografías sobre exposiciones de frutas organizadas oficialmente, vistas del edificio de la fábrica de conservas de frutas Arcanco, en Godoy Cruz, y plantaciones de manzanos en Tunuyán ilustraban el capítulo, que pretendía poner de manifiesto la activa promoción realizada por el ejecutivo local a favor de la nueva -o renovada- agroindustria.

En 1939 se publicó el Álbum de Mendoza: reseña geográfica, histórica, cultural, política, comercial e industrial. De factura semejante a otras publicaciones comunes en las primeras décadas del siglo Xx, figuraba como realizado por Ramón Francisco Morey. Aunque aparecía como una empresa editorial particular, sus abundantes referencias a la acción de gobierno de las autoridades en turno lo convierten en una obra evidentemente respaldada por la dirigencia política.

Una sección del libro informaba sobre los progresos en materia de fruticultura y sus derivados industriales, señalando las especies propias de cada zona. En el departamento de Santa Rosa, por ejemplo, se cultivaban duraznos y ciruelas aptos para su consumo directo o desecado. En Tunuyán se obtenían excelentes manzanas, comparables a las californianas. Su

\footnotetext{
${ }^{37} \mathrm{Su}$ actuación abarcó otras actividades: estaciones de servicio en Godoy Cruz, establecimientos sidreros en Tunuyán, la región productora de manzanas de la provincia. Diccionario, 1945, pp. 110-111.

${ }^{38}$ Tres, 1938.
} 
abundancia y calidad habían permitido el desarrollo de la industria de la sidra. Tupungato brindaba nueces en cantidades, mientras otras zonas producían peras, cerezas y membrillos, industrializados en dulce. El principal renglón de la exportación de frutas era, sin duda, la uva de mesa, enviada a Europa y Estados Unidos, además de ser consumida en el país. Estas afirmaciones eran refrendadas con datos de la Dirección de Estadística Provincial. Según estas cifras, en el año agrícola 1937-1938 habían salido de la provincia un total de $105419000 \mathrm{~kg}$ de frutas, correspondiendo la mitad a uvas de mesa. Por su parte, la industrialización de estas frutas indicaba que, durante 1938, los rubros más destacados habían sido la elaboración de dulces de duraznos y de extracto concentrado de tomates. ${ }^{39}$

\section{CONSIDERACIONES FINALES}

Los datos presentados hasta aquí parecen mostrar que las políticas dirigidas a la fruticultura durante la década de 1930 estuvieron centradas de modo notorio en publicidades oficiales y orientación práctica a los productores más que en una legislación específica y completa. Dicho de otra manera, la publicidad, durante esos años, adquirió el carácter de una verdadera política de Estado. Este rasgo puede ser visualizado en otros campos de la actividad gubernamental. De hecho, las políticas reguladoras de la producción -elemento central del accionar público- fueron acompañadas por constantes apelaciones a la importancia de consumir mercaderías nacionales como estrategias complementarias destinadas a enfrentar la crisis. Haciendo de la necesidad virtud, el Estado teñía de "valores patrióticos" las prácticas económicas aconsejadas. Comprar, usar, beber y comer lo producido por las tradicionales agroindustrias argentinas, o por la bastante reciente industria textil, se convertían en actividades sustentadoras de la identidad nacional, en acciones cargadas de "argentinidad". ${ }^{40}$

Pero si en los casos citados la propaganda estaba dirigida preponderantemente al mercado interno, en el tema de la fruticultura los receptores propuestos fueron, además, los consumidores del exterior. La revista $M A N$ estaba dirigida explícitamente a ellos, y era repartida en consulados argentinos con la intención de llegar a esos públicos confiando en la acción repetidora de los funcionarios consulares. Pero la apelación a los habitantes del país poseía otro sentido. Las constantes referencias a las bondades de la fruta argentina, la prolija transcripción de su presencia creciente en las estadísticas de exportación, eran elementos destinados a construir con-

${ }^{39}$ Álbum, 1939.
${ }^{40}$ Girbal y Ospital, "Vivir”, 2005, pp. 49-66. 
sensos en torno a las políticas implementadas por el gobierno nacional. En una etapa signada por las cortapisas a la participación política amplia, se intentaba mostrar los aspectos exitosos de la administración conservadora. La crisis -bastante superada ya en 1935- había obligado a los sectores dirigentes a encontrar alternativas al viejo modelo económico. Mientras el Ministerio de Hacienda elaboraba y ponía en práctica las medidas anticíclicas conocidas, el Ministerio de Agricultura, de perfil mucho más técnico y con un grupo de funcionarios medios que se mantenían a pesar de los cambios en la cúpula ministerial, enseñaba a los productores a cultivar excelente fruta, estimulaba a los argentinos a consumirla como práctica saludable y buscaba alentar el orgullo nacional en torno al nuevo producto que venía a sumarse a la "ya larga lista de las cosas buenas y sabrosas con que nuestra tierra fecunda contribuye a la salud y al bienestar del mundo".

Si la cuestión recibió atención en el ámbito nacional, la región vitivinícola, golpeada por la crisis y con su producción fuertemente regulada desde 1936, encontró en la fruticultura una alternativa complementaria importante. La provincia mendocina poseía tierras apropiadas para el cultivo de frutas diversas y, de hecho, venía produciéndolas a escala artesanal. Los propietarios de plantaciones de vid, obligados en muchos casos a desarraigar las cepas, ocuparon esas hectáreas con uvas de mesa, peras, duraznos o tomates -según las zonas- buscando recuperar, en el mercado interno, el espacio antes ocupado por sus vinos. Al mismo tiempo, comenzaron a desarrollar una incipiente industria conservera para diversificar su producción y reposicionarse económicamente. El camino fue compartido por los bodegueros regionales, inversores también en la nueva actividad.

Estado nacional y dirigencia provincial coincidieron en las acciones destinadas a promover el nuevo renglón de la agricultura argentina. De ser "el país de los ganados y las mieses", Argentina podía convertirse, también, en un actor interesante en el mercado internacional como proveedor de frutas. Esa era, al menos, la publicitada orientación que adquiría la política oficial en ese rubro, como una herramienta más de las esgrimidas para superar el impacto de la crisis internacional y recuperar equilibrios regionales internos.

\section{BiBLIOGRAFÍA}

Álbum de Mendoza, reseña geográfica, histórica, cultural, política, comercial e industrial, Mendoza, Ramón Francisco Morey, 1939.

Almanaque del Ministerio de Agricultura de la Nación, Buenos Aires, Ministerio de Agricultura de la Nación, 1937, pp. 18 y 213-221. 
Almanaque del Ministerio de Agricultura de la Nación, Buenos Aires, Ministerio de Agricultura de la Nación, 1938, pp. 79 y 357-369.

Bandieri, Susana, Historia de la Patagonia, Buenos Aires, Sudamericana, 2005. y Graciela Blanco, "La fruticultura en el Alto Valle del Río Negro. Auge y crisis de una actividad capitalista intensiva (1930-1980)", Revista de Historia, Universidad Nacional de Comahué, núm. 2, 1991, Neuquén, pp. 127-141. "Pequeña explotación, cambio productivo y capital británico en el Alto Valle del Río Negro, 1900-1948”, Quinto Sol, Universidad Nacional de la Pampa, vol. II, núm. 2, 1998, Santa Rosa, pp. 25-63.

Bendini, Mónica y Cristina Pescio (coords.), Trabajo y cambio técnico. El caso de la agroindustria frutícola en el Alto Valle, Buenos Aires, La Colmena, 1996.

BLACHA, LuIS, "Burocracia y política agraria en la Argentina (1930-1943). Acción y visión de la clase política" en V Jornadas de investigación y debate. Trabajo, propiedad y tecnología en la Argentina rural del siglo XX, Bernal, Universidad Nacional de Quilmes, 2008.

"Decreto", La Chacra, núms. de febrero y mayo de 1937, Buenos Aires, pp. 44-45 y 35-36, respectivamente.

"Decreto reglamentario núm. 96066”, La Chacra, núm. de marzo de 1937, Buenos Aires, pp. 44-45.

Diccionario biográfico de hombres de negocios, Buenos Aires, Editorial Veritas, 1945, pp. 110-111.

Dirección de Frutas y Hortalizas, “ifruta! del árbol a la mesa” en Almanaque, Dirección de Propaganda y Publicaciones, Ministerio de Agricultura, 1937.

“Editorial”, Servir, Escuela de Estudios Argentinos, año I, núm. 1, enero de 1936, Buenos Aires, pp. 5-7.

"Fruta sana, buena y barata", MAN. Al Servicio de la Riqueza Argentina, Ministerio de Agricultura de la Nación, núm. 1, marzo de 1937, Buenos Aires.

Girbal-Blacha, Noemí M. y María Silvia Ospital, “'Vivir con lo nuestro.' Publicidad y política en la Argentina de los años 1930", Revista Europea de Estudios Latinoamericanos y del Caribe, Centro de Estudios y Documentación Latinoamericanos, núm. 78, abril de 2005, pp. 49-66.

Girbal-Blacha, Noemí, María Silvia Ospital y Adrián Gustavo Zarrilli, Las miradas diversas del pasado. Las economías agrarias del interior ante la crisis de 1930, Buenos Aires, Edición Nacional Editora e Impresora, 2005.

Girola, Carlos D., Museo Agrícola de la Sociedad Rural Argentina, Argentina, Ministerio de Agricultura, 1920, núm. 18.

, Museo Agrícola de la Sociedad Rural Argentina, Argentina, Ministerio de Agricultura, 1922, núm. 28.

, Museo Agrícola de la Sociedad Rural Argentina, Argentina, Ministerio de Agricultura, 1925-1926, núm. 50. , Museo Agrícola de la Sociedad Rural Argentina, Argentina, Ministerio de Agricultura, 1929, núm. 52. 
GutiéRrez, TALÍA, "Revista La Chacra: industria editorial, agro y representación, 19301955” en Silvia Lázzaro y Guido Galafassi (comps.), Sujetos, política y representaciones del mundo rural. Argentina 1930-1976, Buenos Aires, Siglo XXI/Editora Iberoamericana, 2005, pp. 19-62.

Herl, Irene N. (comp.), Ex Ministerio de Agricultura de la Nación. Reseña histórica de la primera etapa, 1898-1950, Buenos Aires, s. e., 2008, CD.

"Informe de la Dirección de Frutas y Hortalizas", Argentina, Ministerio de Agricultura de la Nación, junio de 1938.

Justo, Agustín P., Momento político, Buenos Aires, s. e., 1939.

Llach, JuAn José, La Argentina que no fue, Buenos Aires, Instituto del Desarrollo, 1985.

Lutscher, Arnaldo M., "Aspectos de la fruticultura argentina", Servir, Escuela de Estudios Argentinos, año I, núm. 1, enero de 1936, Buenos Aires, pp. 90-95.

Mateu, Ana M., "La vitivinicultura" en Primer Congreso de Historia Vitivinícola Regional, Montevideo, noviembre de 2005, CD.

O’Connell, Arturo, "La Argentina en la depresión: los problemas de una economía abierta”, Desarrollo Económico, Instituto de Desarrollo Económico, núm. 92, eneromarzo de 1984, Buenos Aires, pp. 479-514.

Ollivier, Adrián, "La fruticultura argentina y su porvenir", Servir, Escuela de Estudios Argentinos, núm. 1, julio de 1936, Buenos Aires, pp. 237-264.

Ospital, María Silvia, "Más allá de la regulación. Políticas vitivinícolas entre 1935 y 1946", Anuario 6, Centro de Estudios Históricos Carlos Segreti, 2007, Córdoba, pp. 223-238.

PAdrós, J. Simon, "Frigoríficos regionales para frutas", Servir, Escuela de Estudios Argentinos, núms. 24-25, junio-julio de 1938, Buenos Aires, pp. 1787-1803.

"Peras argentinas para exportación”, MAN. Al Servicio de la Riqueza Argentina, Ministerio de Agricultura de la Nación, mayo de 1939, Argentina.

"Presentación”, MAN. Al Servicio de la Riqueza Argentina, Ministerio de Agricultura de la Nación, núm. 1, marzo de 1937, Argentina.

"Riquezas argentinas. Nuestra fruta conquista los mercados del mundo", La Chacra, agosto de 1939, Buenos Aires, pp. 79-81.

"Río Negro", MAN. Al Servicio de la Riqueza Argentina, Ministerio de Agricultura de la Nación, enero de 1938, Argentina.

Ruffini, Martha, "Un nuevo perfil institucional de la Argentina agroexportadora: la creación del Ministerio de Agricultura de la Nación (1898)" en Octavo Congreso Nacional y Regional de Historia Argentina, Buenos Aires, Academia Nacional de la Historia, 1998, pp. 373-382.

SchVarzer, Jorge, La industria que supimos conseguir, Buenos Aires, Planeta, 1996, pp. 153-186.

Tres años de gobierno. Gobernación de Guillermo G. Cano, 1935-1938, Mendoza, s. e., 1938. 